Baxendale, S; McGrath, K; Donnachie, E; Wintle, S; Thompson, P; Heaney, D; (2015) The role of obesity in cognitive dysfunction in people with epilepsy. Epilepsy Behav 10.1016/i.yebeh.2015.01.032.

\title{
Article
}

\section{The Role of Obesity in Cognitive Dysfunction in People with Epilepsy}

Sallie Baxendale ${ }^{1}$ Katherine McGrath ${ }^{2}$ Elizabeth Donnachie ${ }^{2}$, Sue Wintle ${ }^{2}$, Pamela Thompson ${ }^{3}$, Dominic Heaney ${ }^{3}$

${ }^{1}$ Department of Clinical and Experimental Epilepsy, Institute of Neurology, UCL,

${ }^{2}$ Epilepsy Society, Chalfont St Peter, Buckinghamshire, UK

${ }^{3}$ University College Hospital, London

Address for Correspondence:-

Dr Sallie Baxendale

ESRC Epilepsy Society

Chesham Lane

Chalfont St Peter

Buckinghamshire

SL9 ORJ

Tel: +44 1494601353

Fax: +44 2078132516

Email: s.baxendale@ucl.ac.uk

Running Title: The impact of obesity on memory \& IQ

Word Count Abstract : 276

Character Count Title : 68
Tables : $n=2$

References $=n=15$
Figures : $n=0$ 


\section{Summary}

Objective:

In the general population, obesity is associated with accelerated age-related cognitive decline. The impact of obesity in neurological populations who already have a heightened risk of cognitive decline is unknown. This study explored the relationship between obesity and cognitive underfunction in people with medically intractable epilepsy.

\section{Methods:}

Eighty one consecutive admissions for inpatient evaluation for medically intractable epilepsy (36 Females, 45 Males) underwent tests of memory and intellectual function. Optimal level of function was assessed using the National Adult Reading Test - Revised. Measures of underfunction were calculated by subtracting current measures of intellectual ability from the NART IQ. Body Mass Index (BMI) was used as an index of obesity.

\section{Results:}

Twenty nine people had a BMI in the healthy range (36\%), 31 were overweight (38\%) and 21 were obese (26\%). The heathy/overweight/obese groups did not differ in age at the time of assessment, age at seizure onset or optimal level of function (NART IQ). The obese group had a greater degree of suboptimal processing speed and demonstrated a greater degree of underfunction on the Full Scale IQ (FSIQ) measure compared to the healthy weight group. BMI accounted for $14 \%$ of the variance in underfunction in processing speed and $10 \%$ of the underfunction in FSIQ. Controlling for the effects of age, all measures of memory function were significantly correlated with BMI, with poorer scores associated with higher BMls.

\section{Significance:}

A small, but significant proportion of the variance in memory function and intellectual underfunction in people with epilepsy is explained by BMI. Further work is needed to establish whether a reduction in BMI to within healthy limits is associated with improvements in cognitive function in this group.

Key words : Cognitive function, IQ, Memory, Body Mass Index, 


\section{Introduction}

In the general population, obesity is associated with accelerated age-related cognitive decline from middle age onwards[1] . Non dementing adults who are obese perform more poorly on standardised memory tests compared to individuals who are a healthy weight.[2, 3] They also have smaller hippocampi [4], particularly those with central obesity[5]. Central obesity in middle age is also associated with an increased risk of developing dementia in old age [5]. The mechanisms underlying this relationship are complex and multifactorial. Obesity is a biomarker for the cardiovascular risk factors and diseases that have a direct impact on cognitive function, including diabetes and insulin resistance, elevated triglyceride levels, white matter disease, hypertension and hypercholesterolemia.[6]

The impact of obesity on cognitive function in younger neurological populations who have pre-existing, heightened risks of cognitive dysfunction is unknown. The mechanisms of cognitive dysfunction in epilepsy are complex. The underlying pathology, antiepileptic medications and psychological factors all interact with the functional reserve of an individual to shape their cognitive profile. Cognitive functions change over time, with progressive deterioration associated with frequent generalised seizures and stepwise deteriorations following episodes of status epilepticus or seizure related injuries. $[7,8]$

A recent review found that the rates of obesity in people with epilepsy are similar to those found in the general population [9]. Whilst there are no associations between obesity and epilepsy type, duration, or aetiology, obesity rates are higher in patients with refractory than nonrefractory epilepsy (36.9\% vs. $24.6 \%)$. Obesity is also more common in patients treated with polytherapy than those treated with monotherapy (37.7\% vs. $25 \%$ ). Some antiepileptic medications, particularly sodium valproate and pregabalin, have weight gain as a significant side effect [10].

This study explored the relationship between obesity and cognitive function and measures of decline on standardised indices of intellectual and memory function in people with medically intractable epilepsy. The prevalence of memory deficits in this population is already high $^{6}$, due to a combination of the underlying pathology, treatment effects and psychiatric morbidities ${ }^{7}$ associated with the condition. We hypothesised that effects of obesity on cognitive function seen in the general population would be evident in this neurological population. This study was designed to examine the variance in measures of intellectual decline and memory function that is explained by BMI in people with intractable epilepsy.

\section{Methods}

\section{Design:}

This was a cohort study of 81 consecutive adult patients who were referred for a neuropsychological assessment at our specialist epilepsy assessment service in 2013-2014. 
Participants:

All participants had a clinical diagnosis of epilepsy and were taking at least one antiepileptic medication at the time of assessment. At the time of the assessment, all participants were medically intractable i.e. they continued to experience seizures despite taking antiepileptic medications. All the participants in this study spoke English as a first language. Patients who had a diagnosis of Non Epileptic Attack Disorder (NEAD), or who were unable to complete the neuropsychological assessment due to sensory deficits or psychiatric disturbance were excluded from the study. The majority of the participants had focal epilepsy $(n=77) ; 36$ had a temporal lobe focus; 41 had an extra temporal focus or difficult to localise epilepsy; four had generalised epilepsy. All participants underwent a 3T structural MRI scan. See Table 1.

The clinical and demographic characteristics of the sample are presented in Table 2. All participants underwent a medical interview at the time of their admission to the ward which documented their medical history and all previous diagnoses. None of the participants had been given a diagnosis of sleep apnoea at the time of their assessment, but sleep studies were not conducted during their admission to investigate this possibility. One participant had a diagnosis of type 1 diabetes; none had developed type 2 diabetes. 16 participants had evidence of white matter disease on MRI. In 5 of the 16, the white matter lesions were the only abnormalities evident on MRI.

$<<$ Table 2 about here >>

Neuropsychological Tests:

The IQs derived from the National Adult Reading Test - Revised[11] were used to provide a measure of each participants' optimal level of intellectual function. (5.8 points were subtracted to allow for the re-standardisation of the Wechsler Adult Intelligence Scale -IV - WAIS-IV).

All participants completed WAIS-IV UK Edition [12]. The Verbal Comprehension, Perceptual Reasoning, Working Memory and Processing Speed indices were used as measures of intellectual function. The list learning and list retention score from the BIRT Memory and Information Processing Battery (BMIPB)[13] were used as measures of verbal learning and recall respectively. In the list learning task the patient is aurally presented with a list of 15 words to learn over trials and is then required to recall them following exposure to a distractor list. The design learning and design recall measures from the BMIPB were used as measures of visual learning and recall respectively. In the design learning task the patient is exposed for 10 seconds to a design that has nine features and is required to reproduce it over five trials. Recall is tested following exposure to a distractor design. These tests have been described previously and have been shown to be sensitive to hippocampal pathology.[14, 15]

A measure of cognitive underfunction was calculated for each index of intellectual function by subtracting the index score from the NART IQ. In the general population $\mathrm{BMI}$ is negatively correlated with measures of intellectual function [16]; those with lower IQs are more likely to become obese than more able individuals [17]. In addition to underlying genetic factors, people with lower intellectual reserves, in particular deficits in executive functions, may make poorer diet choices than those 
with stronger intellectual abilities [17-19]. We controlled for this pattern in our study by creating individual measures of cognitive underfunction for each participant. By subtracting each patient's current level of function from reliable measures of their optimal level of ability we ensured that the measures of intellectual underfunction we used in the analyses were relative to each patient's optimal level of function rather than the norms in the general population.

Reliable estimates of an individual's optimal memory function are not available. Measures of underfunction can only be inferred using standardised neuropsychological tests. The memory scores were converted to z scores using the means and standard deviations from published age referenced norms for each test, to allow statistical comparisons [12,13].

76 of the participants completed the Hospital Anxiety and Depression Scale yielding scores for anxiety and depression.

Body Mass Index:

All patients undergo a general health screen when they are admitted to the hospital and their weight and height is recorded. Body mass index was calculated using the following formula $B M I=$ mass $(\mathrm{kg}) /(\text { height }(\mathrm{m}))^{2}$. Participants with a BMI less than or equal to 18.4 were classified as underweight. Participants with a BMI between 18.524.9 were classified as healthy weight. Participants with a BMI between 25 and 29.9 were classified as overweight. Participants with a BMI of 30 or over were classified as obese.

\section{Statistical Methods:}

Partial correlations, controlling for age at time of assessment, were used to examine the relationship between $\mathrm{BMI}$ and neuropsychological test scores. ANOVAs were used to examine the differences between the healthy, overweight and obese groups on the neuropsychological measures.

Regression analyses were used to examine the contribution of BMI to the variance in neuropsychological scores. The correlation coefficient squared (adjusted $R^{2}$ ) was used as a measure of the amount of variability in each memory score that was explained by the model.

\section{Results}

\section{Body Mass Index}

None of the participants were underweight; 29 had a BMI in the healthy range (36\%), 31 were overweight $(38 \%)$ and 21 were obese $(26 \%)$. There was no difference between the three groups (Healthy vs Overweight vs Obese) in their age at the time of assessment $(F=1.3, d f=2, p>0.05)$, age at seizure onset $(f=0.3, d f=2, p>0.05)$ or optimal level of function NART IQ $-(\mathrm{f}=0.11, \mathrm{df}=2, \mathrm{p}>0.05)$. Similarly the three groups did not differ in their anxiety or depression scores on the HADS (Anxiety $\mathrm{f}=0.20, \mathrm{df}=2$, $p>0.05$; Depression $f=0.44, d f=2, p>0.05$ ).

The participants with white matter lesions did not significantly differ from those without, in their BMI ( $\mathrm{t}=-1.7, \mathrm{df}=79, \mathrm{p}>.05)$. 


\section{Epilepsy Type and Antiepileptic Medications}

Epilepsy type was not associated with weight classification in this sample (Chi square $=5.6, \mathrm{df}=5, \mathrm{p}>0.05)$. See Table 1. Similarly, the number of antiepileptic medications taken was not related to the weight classifications (Chi square $=5.2, d f=5, p>0.05$ ). See Table 1. Seventeen participants were taking sodium valproate, an antiepileptic medication that has weight gain as recognised side effect. However in our sample the participants taking sodium valproate did not have a higher BMI than those who were not taking the drug $(t=-0.63, d f=79, p>0.05)$.

\section{Intellectual Function}

The obese group demonstrated greater suboptimal function on the Processing Speed Index $(f=5.8, d f=2, p<0.01)$ and on the Full Scale $I Q(f=3.6, d f=2, p<0.05)$ compared to the healthy weight group.

Unsurprisingly, BMI was significantly correlated with age, with higher BMls seen in the older participants (Pearson corr $=0.2, p<0.05$ ). The relationship between the measures of suboptimal function (Current level - optimal level) and BMI were therefore explored using partial correlations to control for the effects of age on BMI. $\mathrm{BMI}$ was significantly correlated with the degree of underfunction in processing speed (corr $=-.35, p<0.01)$, and Full Scale IQ $(-.29, p<0.01)$. See Table 3. BMI accounted for $14 \%$ of the variance in decline in processing speed and $10 \%$ of the variance in decline in FSIQ in this sample.

$<<$ Tables $2 \& 3$ about here $>$

\section{Memory Function}

All of the measures of memory function were significantly correlated with BMI. (Verbal Learning corr $=-.32, p<0.01$; Verbal Recall corr $=-.27, p<0,01$; Visual Learning corr $=-.31, p<0.01$; Visual Recall corr $=-.19, p<0.05)$.

Linear regression analyses were used to determine the contribution of $\mathrm{BMI}$ and the measures of anxiety and depression from the HADS to the variance in the memory scores. BMI was a significant predictor in the models generated for all four memory measures. The anxiety and depression scores were not significant variables. The adjusted $R^{2}$ values were 0.13 for verbal learning, 0.09 for verbal recall, 0.08 for verbal recall, 0.09 for visual recall. See Table 4. 


\section{Discussion}

$\mathrm{BMI}$ is correlated with the extent of underfunction on a global measure of IQ and slowed processing speed in people with medically intractable epilepsy. The more overweight the patient, the higher the discrepancy between measures of their optimal level of function and their current level of function. BMI accounts for up to $14 \%$ of the variance in slowed processing speed. Approximately ten percent of the variance in memory scores on standardised tests of verbal and visual learning can be also be explained by BMI. Our regression analyses suggest that BMI is a more powerful predictor of memory impairment than measures of anxiety and depression. Although the participants in this study all had medically intractable epilepsy, they were a heterogeneous sample in terms of their underlying pathology, type of epilepsy and anti epileptic medication regimes. Nevertheless a high BMI emerged as a significant predictor of cognitive underfunction.

With an average age in their mid-thirties, the participants in this study are significantly younger than those who are typically reported in the obesity/cognitive decline literature. This explains in part, the absence of obesity related health problems such as diabetes and sleep apnoea in this sample. However, it is noteworthy that the presence of white matter lesions was not related to BMI at this stage in the participant's life. The mechanisms driving the relationship between obesity and cognitive function in this sample are unknown and deserve further study.

\section{Limitations:}

Our measure of intellectual underfunction was based on the NART which has a restricted range in its estimates of premorbid IQ [20]. We did not have data on the educational or socioeconomic status of the participants, although these measures can also be of limited value in people whose education and employment opportunities have been limited by their condition. This was a brief pilot study, based on an audit of clinical data, designed to explore the value of this avenue of research in this patient group. Ideally cognitive decline should be measured in a longitudinal study design.

BMI is a relatively crude measure of health and does not take into account muscle mass, fat distribution or other measures of cardiovascular health and fitness. The presence of central obesity may be a particular risk factor for memory decline and accelerated hippocampal volume loss in the general population [5]. Further work is underway to examine the relationship between measures of cognitive decline in this population and more detailed measures of cardio vascular fitness including hip/waist ratio, blood pressure, eGFR and ECG data.

We did not examine dosage of individual medications as this is difficult to compare across different medications. However the prescription patterns and dosages for the majority of antiepileptic medications are not routinely adjusted for the weight of the patient and this is unlikely to account for our findings.

\section{Interpretation:}

Whilst correlation does not equate to causation, these findings suggest the possibility of cognitive improvement following a reduction in BMI in this group. In the healthy population improvements on tests of memory and executive function have been recorded following weight loss in obese individuals [4, 21, 22]. Although further work is necessary to see whether this pattern holds true in this population, this raises the possibility that lifestyle counselling could form an integral part of neuropsychological

rehabilitation packages for cognitive complaints in this group.


Table 1. MRI Pathology

\begin{tabular}{|l|c|c|}
\hline & Frequency & Percent \\
\hline Normal: No abnormality detected & 35 & 43.2 \\
Hippocampal Sclerosis & 12 & 14.8 \\
Cortical Dysplasia & 11 & 13.6 \\
Dysembryoplastic Neuroepithelial Tumour & 2 & 2.5 \\
Structural Lesion & 8 & 9.9 \\
Hyper intense lesion & 2 & 2.5 \\
White Matter Disease & 5 & 6.2 \\
Surgery & 4 & 2.5 \\
Infarct & 81 & 100.0 \\
Total & 2 & 4.9 \\
\hline
\end{tabular}


Table 2: Clinical \& Demographic Characteristics of the Participants

\begin{tabular}{|l|l|l|l|}
\hline & Normal Weight & Overweight & Obese \\
$\mathrm{N}=29$ & $\mathrm{~N}=31$ & $\mathrm{~N}=21$ \\
\hline Epilepsy Type & Focal $\mathrm{n}=28$ & Focal $\mathrm{n}=30$ & Focal $\mathrm{n}=19$ \\
$(\mathrm{n}=17$ temporal $)$ & $(\mathrm{n}=6$ temporal $)$ & $(\mathrm{n}=5$ temporal $)$ \\
& Generalised $\mathrm{n}=1$ & Generalised $\mathrm{n}=1$ & Generalised $\mathrm{n}=2$ \\
\hline No. of AEDs & $1-\mathrm{n}=7$ & $1-\mathrm{n}=3$ & $1-\mathrm{n}=2$ \\
& $2-\mathrm{n}=13$ & $2-\mathrm{n}=12$ & $2-\mathrm{n}=7$ \\
& $>2-\mathrm{n}=9$ & $>2-\mathrm{n}=16$ & $>2-\mathrm{n}=12$ \\
\hline Age at Assessment & $32.0(10.5)$ & $35.6(11.0)$ & $36.5(10.0)$ \\
\hline Age at epilepsy onset & $18.2(6.9)$ & $18.2(12.5)$ & $15.8(12.3)$ \\
\hline
\end{tabular}


Table 3: Relationship between BMI and Measures of Intellectual Function

\begin{tabular}{|c|c|c|c|}
\hline & $\begin{array}{l}\text { Partial Correlation } \\
\text { with BMI (controlling } \\
\text { for age) }\end{array}$ & $\mathrm{R}^{2}$ & $\begin{array}{l}\text { \% of variance } \\
\text { explained by } \\
\text { BMI }\end{array}$ \\
\hline $\begin{array}{l}\text { Verbal Comprehension } \\
\text { Underfunction Index }\end{array}$ & Corr $=-.11$ n.s & 0.01 & $1 \%$ \\
\hline $\begin{array}{l}\text { Perceptual Reasoning } \\
\text { Underfunction Index }\end{array}$ & Corr $=-.10 \mathrm{n} . \mathrm{s}$ & 0.01 & $1 \%$ \\
\hline $\begin{array}{l}\text { Working Memory } \\
\text { Underfunction Index }\end{array}$ & Corr $=-.17$ n.s & 0.02 & $2 \%$ \\
\hline $\begin{array}{l}\text { Processing Speed } \\
\text { Underfunction Index }\end{array}$ & Corr $=-.36(p<0.001)$ & 0.14 & $14 \%$ \\
\hline $\begin{array}{l}\text { Full Scale IQ } \\
\text { Underfunction Index }\end{array}$ & Corr $=-.31(p<0.01)$ & 0.09 & $10 \%$ \\
\hline
\end{tabular}

n.s. not significant $p>0.05$ 
Table 4. Linear Regression Analyses: Memory scores as independent variables \& BMI, anxiety \& depression as predictor variables.

\begin{tabular}{|c|c|c|c|c|}
\hline Verbal Learning Model & B & Std. Error & $\mathrm{t}$ & Sig. \\
\hline (Constant) & 67.476 & 6.273 & 10.757 & .000 \\
\hline BMI & -.657 & 216 & -3.037 & .003 \\
\hline HADS Anxiety & -.139 & .355 & -.392 & .696 \\
\hline HADS Depression & -.413 & .367 & -1.124 & .265 \\
\hline \multicolumn{5}{|l|}{ Visual Learning Model } \\
\hline (Constant) & 50.230 & 4.473 & 11.229 & .000 \\
\hline $\mathrm{BMI}$ & -.500 & .154 & -3.241 & .002 \\
\hline HADS Anxiety & -.356 & .253 & -1.408 & .164 \\
\hline HADS Depression & .182 & 261 & .697 & 488 \\
\hline \multicolumn{5}{|l|}{ Verbal Recall Model } \\
\hline (Constant) & 15.258 & 1.975 & 7.724 & .000 \\
\hline BMl & -.165 & .068 & -2.420 & .018 \\
\hline HADSanx & -.075 & .112 & -.666 & .508 \\
\hline HADSdep & -.106 & .116 & -.921 & .360 \\
\hline \multicolumn{5}{|l|}{ Visual Recall Model } \\
\hline (Constant) & 10.773 & 1.211 & 8.893 & .000 \\
\hline BMI & -.100 & .042 & -2.391 & .019 \\
\hline HADS Anxiety & -.086 & .068 & -1.249 & .216 \\
\hline HADS Depression & -.027 & .071 & -.376 & .708 \\
\hline
\end{tabular}

\section{Authors Statements}

We confirm that we have read the Journals position on issues involved in ethical publication and affirm that this report is consistent with those guidelines. The work described above conforms to the Journal's guidelines for ethical publication.

None of the authors has any conflict of interest to disclose. 


\section{Reference List}

[1] Dahl A, Hassing LB, Fransson E, Berg S, Gatz M, Reynolds CA et al. Being overweight in midlife is associated with lower cognitive ability and steeper cognitive decline in late life. J Gerontol A Biol Sci Med Sci 2010;65:57-62.

[2] Cournot M, Marquie JC, Ansiau D, Martinaud C, Fonds H, Ferrieres $\mathrm{J}$ et al. Relation between body mass index and cognitive function in healthy middleaged men and women. Neurology 2006;67:1208-14.

[3] Birdsill AC, Carlsson CM, Willette AA, Okonkwo OC, Johnson SC, Xu G et al. Low cerebral blood flow is associated with lower memory function in metabolic syndrome. Obesity (Silver Spring) 2013;21:1313-20.

[4] Fotuhi M, Do D, Jack C. Modifiable factors that alter the size of the hippocampus with ageing. Nat Rev Neurol 2012;8:189-202.

[5] Jagust W, Harvey D, Mungas D, Haan M. Central obesity and the aging brain. Arch Neurol 2005;62:1545-8.

[6] Sellbom KS, Gunstad J. Cognitive function and decline in obesity. J Alzheimers Dis 2012;30 Suppl 2:S89-S95.

[7] Baxendale S, Thompson P. Beyond localization: the role of traditional neuropsychological tests in an age of imaging. Epilepsia 2010;51:2225-30.

[8] Witt JA, Helmstaedter C. Should cognition be screened in new-onset epilepsies? A study in 247 untreated patients. J Neurol 2012;259:1727-31.

[9] Janousek J, Barber A, Goldman L, Klein P. Obesity in adults with epilepsy. Epilepsy Behav 2013;28:391-4.

[10] Chukwu J, Delanty N, Webb D, Cavalleri GL. Weight change, genetics and antiepileptic drugs. Expert Rev Clin Pharmacol 2014;7:43-51.

[11] Nelson H, Willison JR. The Revised National Adult Reading Test - Test Manual. 1991. Windsor UK, NFER-Nelson.

[12] Wechsler D. Wechsler Adult Intelligence Scale - Fourth UK Edition (WAIS-IV UK). 2010. London, Pearson Education Ltd.

[13] Oddy M, Coughlan A, Crawford J. BIRT Memory and Information Processing Battery. 2009. Burgess Hill, West Sussex, Brain Injury Rehabilitation Trust.

[14] Baxendale SA, van PW, Thompson PJ, Connelly A, Duncan JS, Harkness WF et al. The relationship between quantitative MRI and neuropsychological functioning in temporal lobe epilepsy. Epilepsia 1998;39:158-66.

[15] Baxendale SA, Thompson PJ, Kitchen ND. Postoperative hippocampal remnant shrinkage and memory decline: a dynamic process. Neurology 2000;55:243-9.

[16] Yu ZB, Han SP, Cao XG, Guo XR. Intelligence in relation to obesity: a systematic review and meta-analysis. Obes Rev 2010;11:656-70. 
[17] Belsky DW, Caspi A, Goldman-Mellor S, Meier MH, Ramrakha S, Poulton R et al. Is obesity associated with a decline in intelligence quotient during the first half of the life course? Am J Epidemiol 2013;178:1461-8.

[18] Kanazawa S. Intelligence and obesity: which way does the causal direction go? Curr Opin Endocrinol Diabetes Obes 2014.

[19] Yesavage JA, Kinoshita LM, Noda A, Lazzeroni LC, Fairchild JK, Taylor J et al. Effects of body mass index-related disorders on cognition: preliminary results. Diabetes Metab Syndr Obes 2014;7:145-51.

[20] Spinks R, McKirgan LW, Arndt S, Caspers K, Yucuis R, Pfalzgraf CJ. IQ estimate smackdown: comparing IQ proxy measures to the WAIS-III. J Int Neuropsychol Soc 2009;15:590-6.

[21] Siervo M, Arnold R, Wells JC, Tagliabue A, Colantuoni A, Albanese E et al. Intentional weight loss in overweight and obese individuals and cognitive function: a systematic review and meta-analysis. Obes Rev 2011;12:968-83.

[22] Siervo M, Nasti G, Stephan BC, Papa A, Muscariello E, Wells JC et al. Effects of intentional weight loss on physical and cognitive function in middle-aged and older obese participants: a pilot study. J Am Coll Nutr 2012;31:79-86. 